\title{
关于顶管工程对地面沉降影响的研究
}

洪江生

汕头市市政工程总公司

DOI:10.32629/ems.v1i1.284

[摘 要] 顶管施工是继盾构施工之后发展起来的一种土层地下工程施工方法, 它不需要开挖面层, 并且能够穿越公路、铁道、河川、地面建 筑物、地下构筑物以及各种地下管线等, 是一种非开挖的铺设地下管道的施工方法。顶管施工具有设备少、工序简单、工期短、造价低、施工 速度快、无须开挖面层等优点, 因此, 这种施工方法在建筑物众多、管线错综复杂的城市里具有突出的优势。但同时, 顶管施工由于改变了土 体原有的应力状态, 就必然会引起被穿越的地层受到扰动和发生地层损失, 从而引起地表的沉降或隆起, 尤其是在软弱土层、砂土、粉砂及卯 石等稳定性差的土层中该现象更为严重。而在城市中, 高大的建筑物往往会有较深的基础埋置在土层中,如果顶管施工过程中产生了过量 的地面沉降或隆起, 这对周围建筑甚至整个城市发展都会带来严重影响。所以,研究顶管工程对地面沉降影响不仅是对顶管施工的工艺完 善,更是对城市基础设施建设具有重要意义。

[关键词] 顶管工程;地面沉降; 影响; 探究

\section{1 导致地面沉降的原因}

顶管施工过程中, 导致地面沉降的因素纷繁复杂, 但大体可以 分为主观因素和客观因素两个方面。

主观因素

1.1 地面损失造成沉降

1.1.1 开挖面支护压力大小的影响

理论上讲, 掘进机在顶进过程中, 如果支护压力小于掘进机所 处土层的最小土压力时, 容易导致临界面的佣塌, 反映在地面上就 是地面的下沉甚至倜塌。另一方面, 如果支护压力大于掘进机所处 地层的被动土压力时, 就会引起地面的凸起, 支护压力大小变化引 起的土体变形主要是地面的坚向位移, 但是由于存在挤土效应, 支 护压力的大小变化同样也能引起土体的横向位移, 由于顶管施工 引起的挤土效应, 当支护压力大于土的被动压力时, 产生挤土作用, 掘进机前方土体要向两侧及前部挤压。因此, 由挤土效应的存在, 支 护压力过大能够引起土体的坚向位移和水平位移。

工具管向前顶进时, 掘进面土体造成较大的影响, 开挖时土体 向工具管移动, 坉塌, 应力降低土体松动范围超出了工具管。必将造 成工具管和后续管周围的地层也被松动, 因此地层有了损失。损失 了地层, 自行密实必然造成地面沉降。这种情况在刃口工具管, 开敞 式工具管中不论是人工开挖还是机械开挖都存在, 三十程度比较 轻。其中地层损失最小的是土压平衡式工具管。

1.1.2 掘进机以及后续管道与土体的摩擦力引起的土体变形 掘进机顶进过程当中, 掘进机及后续管节与土体之间有摩擦 力作用,管节受到摩擦力与顶管顶进的方向相反, 而土体受到的摩 阻力方向是掘进机顶进方向一致的。在未施行注浆减摩的顶管施 工过程中, 这种摩擦力是非常大的, 能够引起土体的水平位移, 进行 了注浆减摩施工工艺的顶管顶进过程中, 摩阻力减少很多, 但是依 然会引起土体位移。

1.1.3 注浆压力引起的土体位移

为了减少顶管顶进过程当中掘进机和后续管节与土体之间的 摩擦力, 常常采用注浆减摩技术, 使管道和土体之间存在一层浆液, 浆液与土体之间存在一定的压力作用,作用方向是径向的,势必引 起径向的土地位移,但此位移一般较小。

1.2 掘进工作面的塌方
塌方造成超量出土, 覆盖层土体松动, 以致地面沉降, 因此要尽 量避免出现塌方。在流沙层中顶管, 可以采取局部气压施工或平衡 法施工, 而不应采取敞开式挖掘, 犹如在软弱土层中施工可采用土 压平衡式、挤压式、局部气压等方式施工,也不应采用敞开式挖掘。 所以施工机具选择不当会造成塌方。塌方的另一个原因就是操作 失误。例如盲目超挖, 泥水平衡或者图塔平衡的平衡力不够, 局部气 压施工中气压不足, 停顶后没有防塌的措施等诸如此类的操作, 管 理不当,都会造成地面沉降。

\section{3 纠偏因素}

土体损失引起土体沉降导致地面变形。在实际现场施工过程 中, 顶管顶力值的修正、顶进速度的控制、顶进方向的纠偏等都是 需要现场操作人员根据实际施工状况进行修改的, 因此在这一过 程中, 主观因素起到了绝大部分的作用。由于现场操作人员的经验 各不相同, 因此对于顶力值的修正和顶进速度的掌控也各不相同, 极易造成刀盘前方上覆土层出现塌陷或隆起等状况。同时纠偏的 过程中也极易造成顶管侧方土体大量损失而造成的上方土层沉 降。

土体损失的原因有以下几种:

掘进机外径与管道差异引起的土体损失。

在顶管施工过程中, 掘进机尾部通过后由于掘进机外径较后 续管道外径大 $19 \mathrm{~mm}$ 。因此, 在掘进机经过后, 土体和后续管节之间 形成了建筑空隙, 虽然在顶管施工过程中, 采用了注浆填充措施, 但 是仍然不可避免会出现土体损失。

开挖面超挖引起的土体损失在掘进机机头开挖过程中, 前舱 压力的过大会引起超挖,即开挖面的超挖,也会引起土体损失。

纠偏引起的土体损失, 工具管在顶进时, 由于各种原因会偏离 设计轴线, 这时需要纠偏, 纠偏方法有挖土纠偏和强制纠偏, 这两种 方法都会产生空隙, 形成土体损失。

顶管顶进时, 因浆液与土层的摩阻力而对周围土体产生拖带 效应,由此牵走部分土体产生的超挖。

管壳移动与地层间的摩擦和剪切作用,引起地层损失。

土体受施工扰动的团结作用, 其中次固结沉降往往要持续几 年,在软土中它所占沉降量的比例大 $36 \%$ 以上。

1.2 客观因素 
在顶管施工过程中,导致出现地面沉降的客观因素相对比较复杂。 其中包括土层地质变化的影响、地下水情况的影响、触变泥浆影响 等。土层地质变化主要是指土体受到扰动后承载力的变化和固结 情况的变化。土体被扰动后,原有的固结模式受到扰动,原平衡状态 也随之被打破,同时管体与土体的剪切作用会造成底层损失。地下 水的存在会导致浮力的增大,从而影响顶力值的大小。同时,地下水 还会降低土体的承载能力,使土体出现流动等现象,进而导致地面 出现沉降。触变泥浆的影响主要体现在注人触变泥浆时的压力对 周围土体产生的挤压形变。同时触变泥浆注人过多时,顶管侧壁的 摩擦力增大,进而导致顶力值的变化,从而会影响刀盘前方土体的 稳定性。

\section{2 控制地面沉降的方法}

顶管施工过程中,地面产生的沉降是无法完全避免的,因此,在 施工过程中,尽可能小的控制地面产生的沉降量更具有实际意义。 控制地面沉降宜早不宜晚，控制方法主要以事前控制和事中控制 为主。

2.1 事前控制

施工前应进行安全评价及分析, 对不满足要求的可采取改善 土地性质的方法对临近建筑物进行保护，同时也可以对地基基础 及建筑结构本身进行加固处理。在施工中进行动态观测,根据观测 结果及时调整各施工参数,实现信息化施工。

事前控制的内容主要包括：工程地质的勘察、顶进线路的选 择、特殊的技术措施以及顶管机的选择等。

工程地质的勘察应包括的内容有: 详细的了解工程概况、工程 地质条件、地下水情况、周围建筑及其基础情况、地下管线的分布 等。根据不同土质、埋深、管径、地下水位等情况设置合理的施工参 数,保证工程质量安全。严格控制管道的偏斜,及时纠偏。要保证顶 管与地表之间有足够的覆土厚度, 一般覆土厚度大于 1.5 倍的管 径。对于一些重要和对位异比较敏感建筑进行保护,同时也可对地 基基础及建筑结构本身进行加固处理。在施工中进行动态观测,根 据观测结果及时调整各施工参数,实现信息化施工。尽量避免顶进 过程中对周围既有管线及建筑物的影响，同时详细掌握施工区域 内的地质情况,尤其对于地下水情况的了解, 减少突发性地下水对 施工的影响。

选择顶进线路时主要应考虑工程地质情况对沉降的影响,应 该优先选择土质良好的地段进行施工，同时直线型线路相比于曲 线形线路对地面产生的沉降影响更小。此外还应尽可能避开管线 密集、周围建筑物较多的区域。

特殊的技术措施是指当地下障碍物较多且清理不会影响建筑 物安全时,可为顶管机增加除障功能。

目前主流的顶管机主要包括泥水平衡式顶管机和土压平衡式 顶管机,这两种顶管机能普遍适用于各种地质条件,但土压平衡式 顶管机在遇到容易产生流沙现象的砂性土时, 需要对土体进行改 良。因此在选择顶管机类型时,还需要根据当地实际工程地质条件 进行选择。

2.2 事中控制
第 1 卷 第 1 期・版本 1.0 2019 年 12 月 8 日 文章类型: 论文|刊号( ISSN):2705-0637

事中控制主要是指在顶管施工过程中, 根据地面沉降量监测 数据、开挖面前方土压力值、推进速度及泥土出土量参数等数据, 尽可能保持顶管保持最佳推進状态。

在顶管推进过程中, 施工单位应按时对推进线路周围地面进 行实时地面沉降量监测,当出现地面沉降量超出预警值时,应立即 停止推进并查找原因, 以保证在顶进过程中地面沉降量始终在安 全允许范围内。

监测开挖面前方土压力值主要是保证顶管对土体产生的压力 与土体自身静止时土压力值相接近, 此时周围土体受到的扰动最 小,地面产生的形变也最小。而当顶管压力与土体自身静止时土压 力相差较大时,则极易造成开挖面的不稳定,导致地面出现隆起或 塌陷。

控制推进速度同样是保证减少对土体的扰动情况，当推进速 度过快时,土体会被过量挤压,必然会增加对土体的扰动,增大土体 的不稳定性。控制泥土出土量是为了控制刀盘前方土压力与土体 自身静止时土压力值的相对持平, 正常情况下的出土量应是理论 出土量的 $98 \% \sim 100 \%$ 。

2.3 地基加固

除以上两种方法外, 在控制地面沉降时还可以采用地基加固 处理方法。该方法既适用于事前控制也同样适用于事中控制。在选 择地基加固处理方法时,选择合理的施工工艺,在对现场进行详细 勘察的基础上,选择合理的顶进路线及机械设备,严格控制各项指 数指标。在顶进过程中,处理好管道接头及密封问题,处理好管道进 出洞的技术问题,减少由此引起的地层损失。常见的地基加固方法 包括高压旋喷桩、水泥土搅拌桩、跟踪注浆等方法。根据不同的土 质情况选择合适的注浆材料。并控制好注浆量、注浆压力和注浆时 间,一般来说,注浆压力与管壁土压力接近时,容易保持土体的稳 定。长距离顶进中还要注意及时补浆。以保证能够对施工区域的地 下管道以及周围的建筑起到有效保护的作用。

\section{3 结束语}

综上所述,引起地面沉降的原因有很多,控制地面沉降的问题 仍然是整个施工过程中最为重要的一个方面。我们不仅应该在理 论上进一步深人研究, 更应该加强在实际施工过程中的现场把控, 同时提高操作人员的施工水平,提高操作人员的工作素养,另外还 应注重事前控制,减少突发状况的发生,优化施工工艺、提高勘察效 率、严格把控施工质量安全等,在施工过程中及时了解掌控土层信 息、开挖面稳定情况等,做到防患于未然。

\section{[参考文献]}

[1]朱世奇,牛雷.关于顶管工程对地面沉降影响的研究 [J]. 建 筑与装饰,2019(8):171-172.

[2]陈锦华,常学林.顶管施工中地面沉降分析及环境对策 [J]. 中国建材科技,2010(06):92-94.

[3]高坤.顶管施工引起地面沉降的机理分析及数值模拟 [J]. 安徽建筑,2018,(04):143-145.

[4]喻军,龚晓南.考虑顶管施工过程的地面沉降控制数值分析 [J].岩石力学与工程学报,2014(S1):2605-2610. 